\title{
Design for a Fry Trap
}

\author{
C. M. BREDER, JR. \\ American Museum of Natural History, New York
}

(Plates I-IV; Text-figure 1)

\section{INTRODUCTION}

T $\checkmark$ HE trap described in this paper was designed to catch fry and slightly larger fishes. It owes much to experience with the small, plastic, funnel traps generally used by aquarists, and perhaps more to discussions with Dr. Robert W. Harrington, Jr., of the Entomological Research Center, State Board of Health of Florida, who was faced by problems similar to our own.

Requirements of the trap were:

1. Must be capable of fishing on the bottom, the surface or at any desired intermediate level.

2. Must permit the transfer of trapped fish to an aquarium or preservative without removal from water or contact with any solid surface.

3. Must be made entirely of non-metallic materials.

4. Must permit the size of the entrance to be changed, so as to variously limit the sizes of organisms admitted.

5. Must make operation by one man, working from shore, a dock or a small boat, easily possible.

6. Must be so constructed as to be readily modified or repaired under field conditions.

Item 1 makes possible a full vertical range of comparative fishing. Since many larval fishes are exceedingly sensitive to handling, even in a very fine net, item 2 proved to be important. It permitted, for instance, the rearing in aquaria of a wide variety of larval and post-larval fishes which otherwise would have been impossible. The use of non-metals throughout (item 3 ) eliminated the possibility of repulsion by incident electrolysis and avoided corrosion problems inherent in immersion. Adjustment of the size of the trap entrance (item 4) greatly restricted damage to the desired fishes by the entry of larger and predatory fishes and invertebrates. Items 5 and 6 are clearly matters of practicality.

\section{Design and Construction}

The body of the trap consists of two separable parts, both made entirely of transparent plastic. The vinyl chloride-acetate copolymer, sold under the trade name "Plexiglas," was used for these, but any equivalent, chemically similar plastic no doubt would be suitable. The pieces were cemented together with Duco Cement. Since this is a solvent for the plastic used, the two pieces became bonded together in what amounted to a very strong weld. The numbers and dimensions of the pieces of plastic used in the two parts of this trap are given in the Bill of Materials, and the appearance of the finished parts is shown in Plate I, Fig. 1, with the two parts both separate and together. The construction is so obvious that fully detailed drawings are not necessary. The side pieces of the box-shaped part are adjusted so that they fit on the $6^{\prime \prime} \times 6^{\prime \prime}$ bottom piece as a perfect square. In making this box it is critical to have the adjacent sides at exact right angles to each other. This is most easily done by making an accurate square jig of four wood strips, about $6^{\prime \prime} \times 1 " \times 1 / 2 "$, nailed to the top of a bench or board. One of these should be readily removable. The freshly cemented pieces may be positioned while the cement is hardening. It is easier to cement two at a time, rather than to try to cement all four at once. The form of the jig is unimportant as long as it maintains the required right angles, but its use is important if several traps are being built serially, for it is highly desirable that the accuracy of these parts permits interchangeability. After the box is formed, a strengthening rim of 
small strips is placed around the open end and a few holes are drilled near the top at both corners of one side. These features are evident in Plate I, where the holes are most clearly seen on the right face of the right hand box as three white dots in each of the two upper corners of that face. When this has been completed, a small fillet of cement should be run around all joints of sides and bottom on the inside of the box, to strengthen it and insure a non-leaking box. Properly made, these boxes may be lifted by one top edge when full of water, with no danger of damage. They may, in fact, be used as temporary aquaria for transporting the contents if they are not too crowded. A lug, for securing a rubber band, is cemented to each of the two apposing sides. It is made of a short and a long piece of the strips used for the lip of the box, the shorter being underneath. These are seen clearly in Plate I, Fig. 1. Their exact position is not critical. It may be found convenient to use a longer piece for the top part of the lug so that it overreaches the smaller under-piece at each end instead of only at the rear end.

The other part of the body of the trap, the "funnel," is similarly made. The triangular piece is isosceles, with the base $51 / 2$ " and the altitude $5 "$. The two side pieces are $5 \% / 8$ " wide so that the "funnel" will slip inside the box, which has that interior dimension. The triangles therefore are cemented to the inside surfaces of these pieces so that the whole part presents a plane surface $5 \%$ " from top to bottom. The entering slit is filed so that if brought together along the triangles they would meet in a line parallel to the sides of the boxes. If these angles are cut by machine or other device with a protractor scale, a setting of $29^{\circ}$ will be accurate enough for all practical purpose. This detail is shown in Text-fig. 1. The width of the entering slit, $S$ in Text-fig. 1, is determined by sliding the sides back and forth along the triangles. The largest-sized slit we have used measures 1/4" and will take moderately-sized Gambusia and Mollienesia as well as fairly large prawns and small crabs. The smallest size we have used, $3 / 32$ ", will not take the above but will take post-larval Brevoortia, new-born Gambusia and Mollienesia, and small, transforming eels. The only crustaceans that have entered the latter trap are tiny prawns and small gammarid amphipods. It is noteworthy that usually these smaller animals do not appear in traps with the larger slits. The funnels are most easily formed with a jig somewhat similar to that described for the box part, but with wood strips at the angles determined by the triangular pieces of plastic. After the funnels have been formed, they should be strengthened with two long strips on their inner surfaces, $L$ in Text-fig. 1 , and a transverse one at the two extremes, most clearly seen in the upper left of Plate I, outer ends. Another transverse piece is cemented to each side, $T$ in Text-fig. 1 , so positioned as to fit snugly against the mouth of the box when the funnel is inserted as seen to the left in Plate I. This is most easily accomplished by placing the funnel in its proper place in the mouth of the box and then cementing these two in place, which guarantees that the fit will be properly snug. A good fit is important because it forms the seal between the two parts and prevents the fishes from "leaking out" at that point.

This completes the plastic construction work. For accuracy, the plastic 1/16" thick should be cut by the supplier unless one has access to a suitable power saw. The strips $1 / 4$ " $\times 1 / 8$ " may be obtained in lengths and cut to size by hack saw. Small variations in them have no bearing on the fitting of the traps.

Good rubber bands, No. $64,31 / 2 " \times 1 / 4 "$, are used in several places. Two are seen in Plate I, holding the two parts of the trap together. In service, two are normally used on each side. The bands were found to last about a month under continual service in warm sea water. Rubber bands are used also for securing the trap to the tail stake, as shown in Plate II, Fig. 3 , and Plate IV, Fig. 6. Here three or four are made into a chain, the two end ones being slipped over the forward ends of the two lugs. To prevent abrasion of the rubber bands, sharp edges of the plastic should be slightly rounded by a fine file. The rubber bands attached to the tail stake should be slipped over the lugs first so that the funnel may be removed without interfering with the tail stake attachment.

Wings of Seran mosquito netting may be as long as necessary. Those shown in the Plates are strips 6" wide and 6' long. They roll up conveniently when not in use and are sewn to the plastic part of the trap with nylon cord. At each outer end, a $6^{\prime \prime}$ piece of the $1 / 4$ " $\times 1 / 8$ " plastic strip is sewn to act as a spreader. For anchoring the bottom-fishing form, a light cord runs from the spreader to a stake (Plate II, Fig. 3).

Seran screen wings sink in sea water and do not require weights to keep them down. To keep the "cork line" up, floats were made of Styrofoam, a very light plastic filled with minute air cells, which is easily cut and does not become water-logged. 


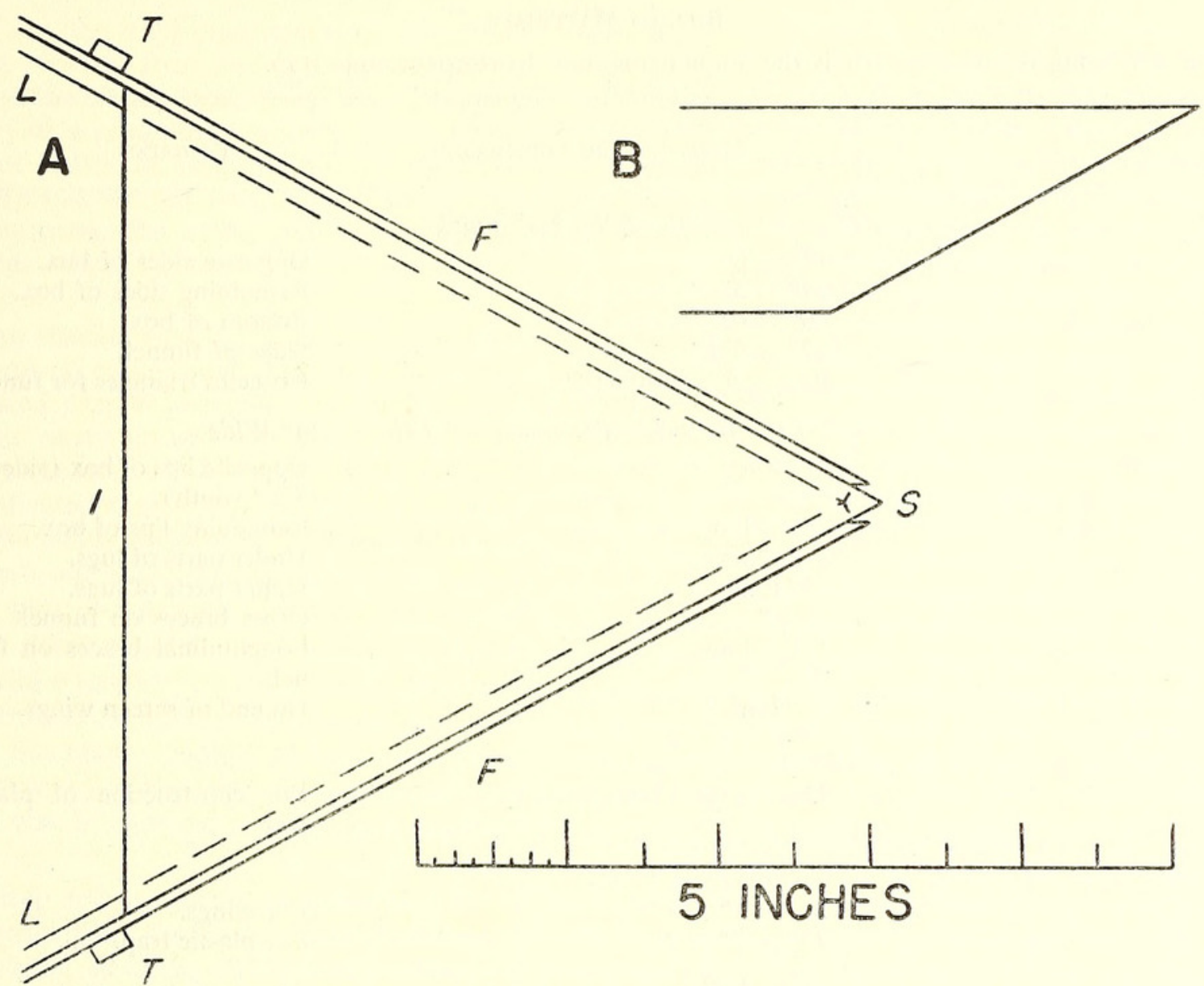

TEXT-FIG. 1. Detail of construction of entrance funnel.

A. Plan view of funnel mouth, set at an opening one-quarter inch wide. $F=$ Edge of side of funnel; $\boldsymbol{I}=$ Isosceles triangle forming top, or bottom of funnel; $\mathbb{L}=$ Longitudinal strengthening strips; $\mathbf{S}=$ Slit, forming entrance to trap; $\mathbf{T}=$ Transverse strip to fit against mouth of box.

B. Enlarged detail of the angle to be filed on the side pieces. It equals one-half the apex angles of the top and bottom triangular pieces.

For surface-fishing, two pieces of Styrofoam, $1 " \times 2$ " $\times 12$ ", will easily float the trap itself, while the wings are supported by smaller pieces sewn along the top edges of the screen (Plate III, Fig. 4). The traps may be attached to a dock or other suitable place by the lines from the wings and, when faced into a tidal flow, will ride nicely with the water force holding them in proper place. These positions must be changed with the change of tide. If this is inconvenient the trap may be anchored to a third place as shown in Plate IV, Fig. 6. Also, the wings may be bridled off as shown in Plate IV, Fig. 7, with a single line for attachment at that end.

When fishing in mid-water, the traps may be set as when fishing at the surface except that each float is connected by a light line of uniform and appropriate length to the trap or wings (Plate III, Fig. 5). It should be noted that the surface fish trap shown in Plate III, Fig. 4 , has the two pieces of Styrofoam attached to the top of the trap, while the traps shown in Plate IV have their fioats attached to the sides flush with the top. In the first instance, the trap floats a little lower, which prevents the entrapment of air when there is some wave movement. This arrangement is not necessary in quiet situations, such as shown in Plate IV; in the latter, floats are placed at the sides so that the contents of the trap are visible at all times.

\section{USE OF TraP}

Protection of small fishes from injury at the time of removing them is simple. It is usually possible to see whether there are fish in the trap before any attempt is made to lift it. In any case, the contents are always visible as soon as the trap is being lifted. The procedure is to release the tie line, if any, to the trap itself, but to leave the wing lines attached to their 
Bill of Materials

The following list of materials is the amount required to construct one trap.

\begin{tabular}{l|l|l}
\hline \hline $\begin{array}{l}\text { No. of } \\
\text { Pieces }\end{array}$ & Materials and Dimensions & Remarks \\
\hline
\end{tabular}

2

2

1

2

2

2

2

2

2

4

4

2

1 tube

4 or more

2

3

9 or more

2

9

Clear Plastic (Plexiglas) 1/16" Thick

$12^{\prime \prime} \times 6^{\prime \prime}$
$12^{\prime \prime} \times 57 / 8 "$
$6^{\prime \prime} \times 6^{\prime \prime}$
$12^{\prime \prime} \times 57 / 8 "$
Base $51 / 2 "$, Altitude 5"

Clear Plastic Strips (Plexiglas) 1/8" Thick $\times 1 / 4 "$ Wide

$$
\text { 6" long }
$$

$61 / 4$ "long

$3 / 4$ " long

1 "long

$57 / 8$ "

$113 / 4$ " long

6" long

\section{Cement}

Duco cement (or equal)

Styrofoam for Floats

$$
\begin{array}{r}
6^{\prime \prime} \times 1 " \times 1 " \\
12^{\prime \prime} \times 2^{\prime \prime} \times 1^{\prime \prime}
\end{array}
$$

Wooden Stakes

$2^{\prime}$ or more in length

\section{Seran Screening}

$6^{\prime} \times 6^{\prime \prime}$ or longer

Rubber Bands

No. $64,31 / 2 " \times 1 / 4 "$

Strong Cord

6 ' or more

1 ' or more
Opposite sides of box.

Remaining sides of box.

Bottom of box.

Sides of funnel.

Isosceles triangles for funnel.

Opposite lips of box (sides of 57/8" width).

Remaining lips of box.

Under parts of lugs.

Upper parts of lugs.

Cross braces on funnel.

Longitudinal braces on funnel.

On end of screen wings.

For construction of plastic trap.

For wings.

For plastic trap.

Old broom handles are satisfactory.

Cut edges bound with Duco cement.

Provide some spares for replacements.

To secure wings to stakes or other.

To float complete trap below surface. support. Thus the entire plastic trap may be tilted up so that the $6^{\prime \prime} \times 6^{\prime \prime}$ piece, called the bottom in the design plans, becomes the bottom in fact and the trap rests in the position shown at the left in Plate I, Fig. 1. In this position, some of the water drains out of the small holes provided in part for this purpose. While the water drains, the rubber bands should be slipped off the lugs on the box sides and the entire funnel lifted out. The box is then free from the rest of the trap and the fishes are, for all practical purposes, swimming in a small aquarium. Here they may rest while the trap is reset with another identical box. The fishes may be released in an aquarium, or killing and fixing agents may be added to the plastic box, as desired. In resetting, the trap should be submerged with the bottom end low so that entrapped air escapes through the small holes in the upper end.

There is no especial merit in the precise dimensions specified for this trap, but it should be borne in mind that the larger it is, the less handy it becomes, and if the weight of water relative to the strength of the box exceeds some critical value, it may burst on handling. 
Thus far, the traps have not been baited and captures resulted from the spontaneous movements of the fishes themselves, since trapping was part of a preliminary survey of the movements of fishes in response to the naturally occurring changes in their environment. For other purposes, the traps could be baited, or electrodes might be used to direct fishes into them.

On the Florida Gulf coast where these traps were used, it was found that when one trap was placed a short distance "behind" another it almost never caught any fishes, which we took as a measure of efficiency. Visual observations indicated that when the traps caught no fishes, the latter were simply not moving about very much, and that empty traps were associated closely with rough water or low temperature when no fishes could be seen in their neighborhood. Mid-water traps caught much less than either surface or bottom traps under our conditions, seemingly indicating that the fishes tended strongly to hug the surface or the bottom -which was in agreement with visual observations.

The trap set as shown in Plate II, Fig. 3, caught principally young Lagodon rhomboides, Menticirrhus saxatilis, Gobiosoma robustum and Mugil curema. The floating trap shown in Plate III, Fig. 4, although catching very few individuals, contained L. rhomboides, Strongylura notata and $M$. curema. The mid-water trap (Plate III, Fig. 5) took only a few $L$. rhomboides. The two traps in Plate IV, set in more confined waters, showed a rather interesting difference in their contents. The leaders of the trap in Fig. 6 came close to the shore line. Its contents were almost entirely small Gambusia and Mollienesia. The trap shown in Fig. 7 rarely contained either of the above but caught small Mugil curema and post-larval Brevoortia. Since the two poeciliids normally hug the shore line closely, they evidently pass around the leader ends unless they nearly reach the shore. Just how the less shore-bound Mugil and Brevoortia avoid the trap only when it is in a position suitable for catching Gambusia is less easily surmised. The three sites shown, a bay shore, the end of a 100-foot dock and a small inlet, are scarcely more than 100 feet from one another. It is evident, that the precise setting of the trap, as well as the size of its aperture, can greatly influence the type of fishes it will catch.

No attempt was made to study in detail the differential catching of invertebrates, but their variety was equivalent to that of the fishes. When left on land, the traps also caught insects and isopods. It is probable that they will be found useful for a variety of purposes other than those for which they were developed. 


\section{EXPLANATION OF THE PLATES}

\section{Plate I}

Fig. 1. The two parts of the fry trap, shown as the "box" and "funnel" separately and together, held by the retaining rubber bands.

\section{Plate II}

Fig. 2. Three complete traps with their screen wings attached and ready for setting.

FIG. 3. A trap fishing on the bottom between tides, held open by three stakes.

\section{Plate III}

Fig. 4. A floating trap fishing from a dock and held out by tidal flow.

Fig. 5. A trap fishing below the surface in midwater, suspended from the surface by means of floats.

\section{Plate IV}

FIG. 6. A floating trap with three-point anchorage, independent of tidal flow.

Fig. 7. A floating trap, so bridled with a spreader as to require a head and tail stake only. The latter is on the left bank just out of the picture. 


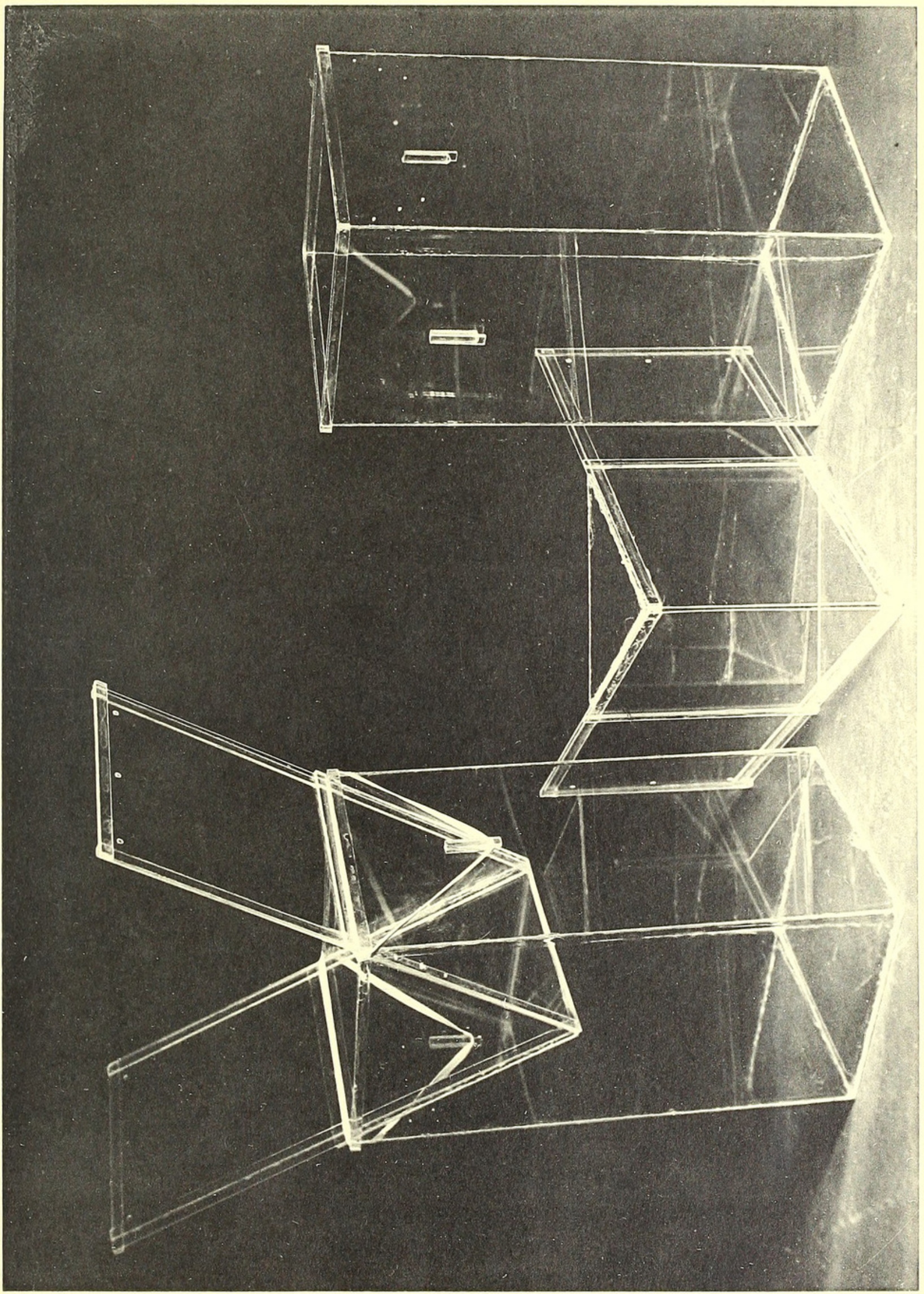

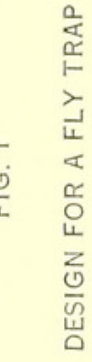




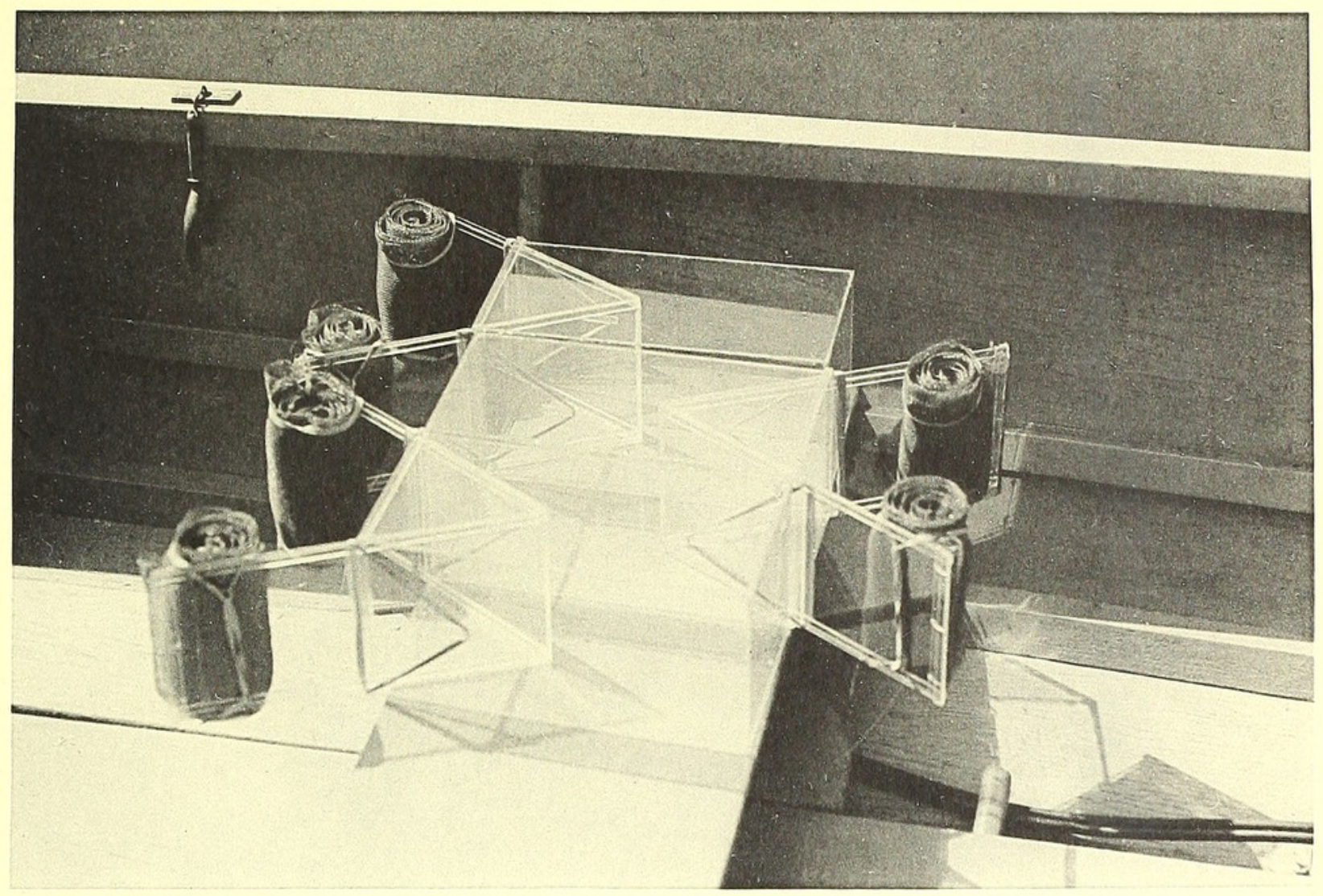

FIG. 2

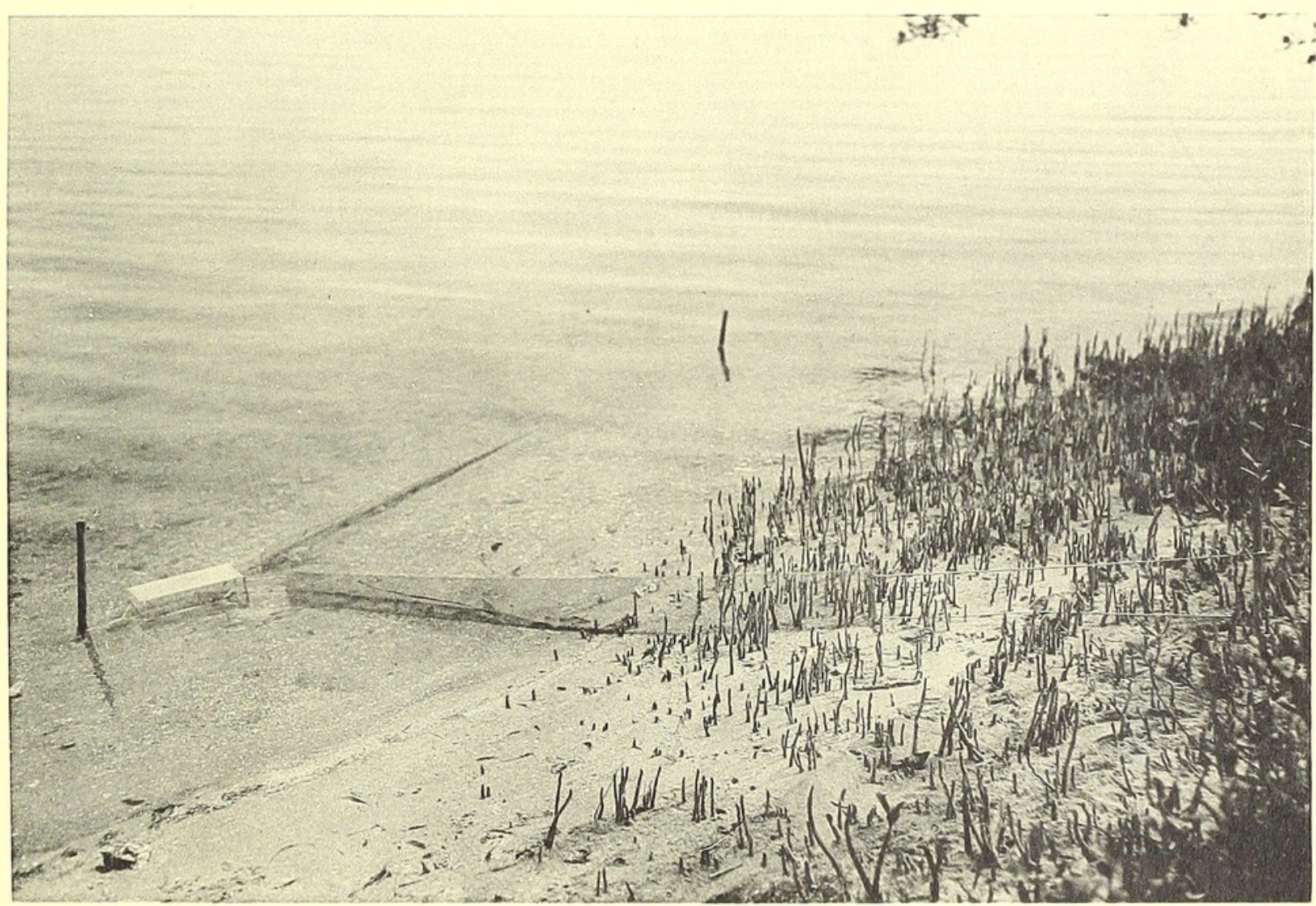

FIG. 3 


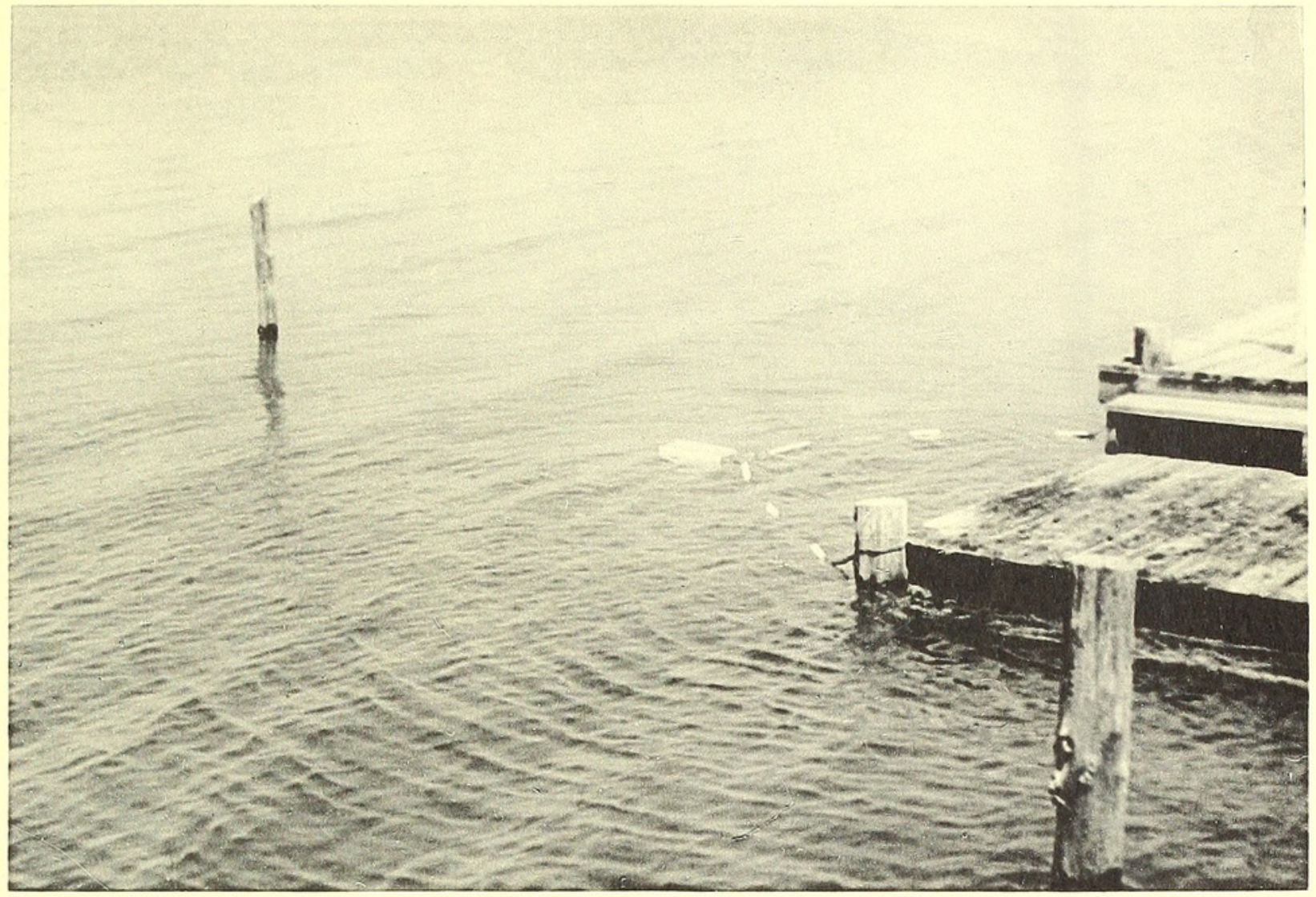

FIG. 4

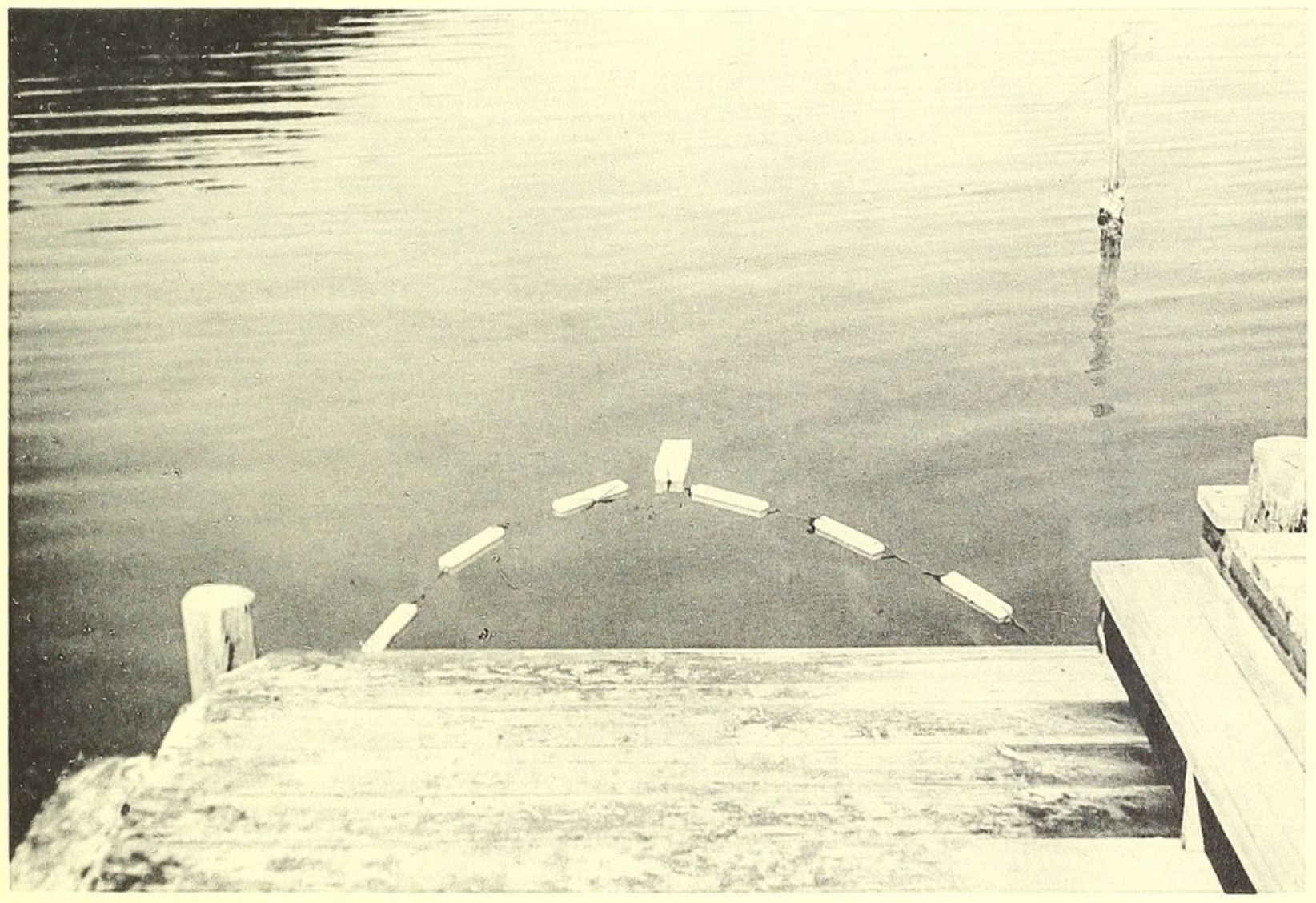

FIG. 5 


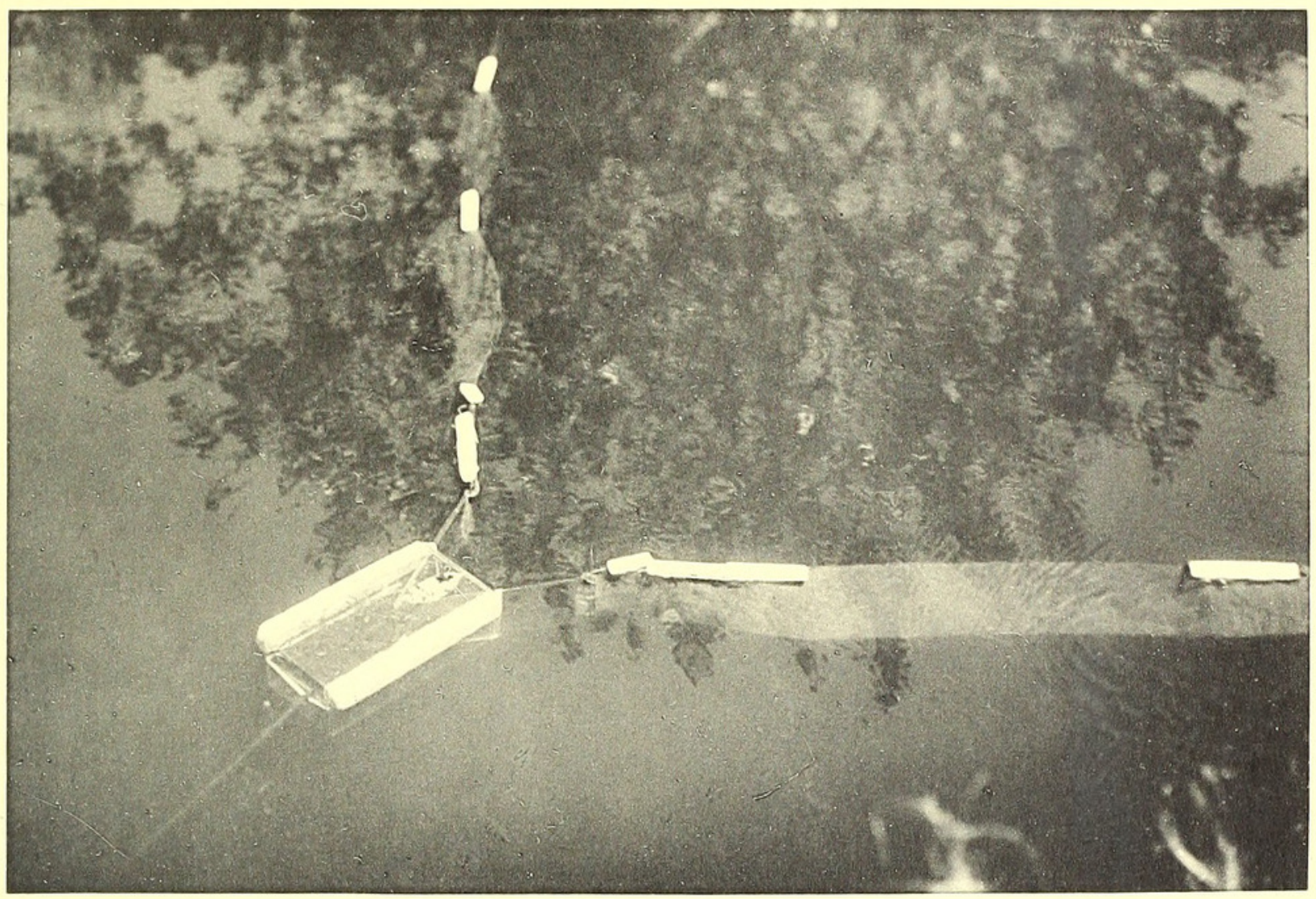

FIG. 6

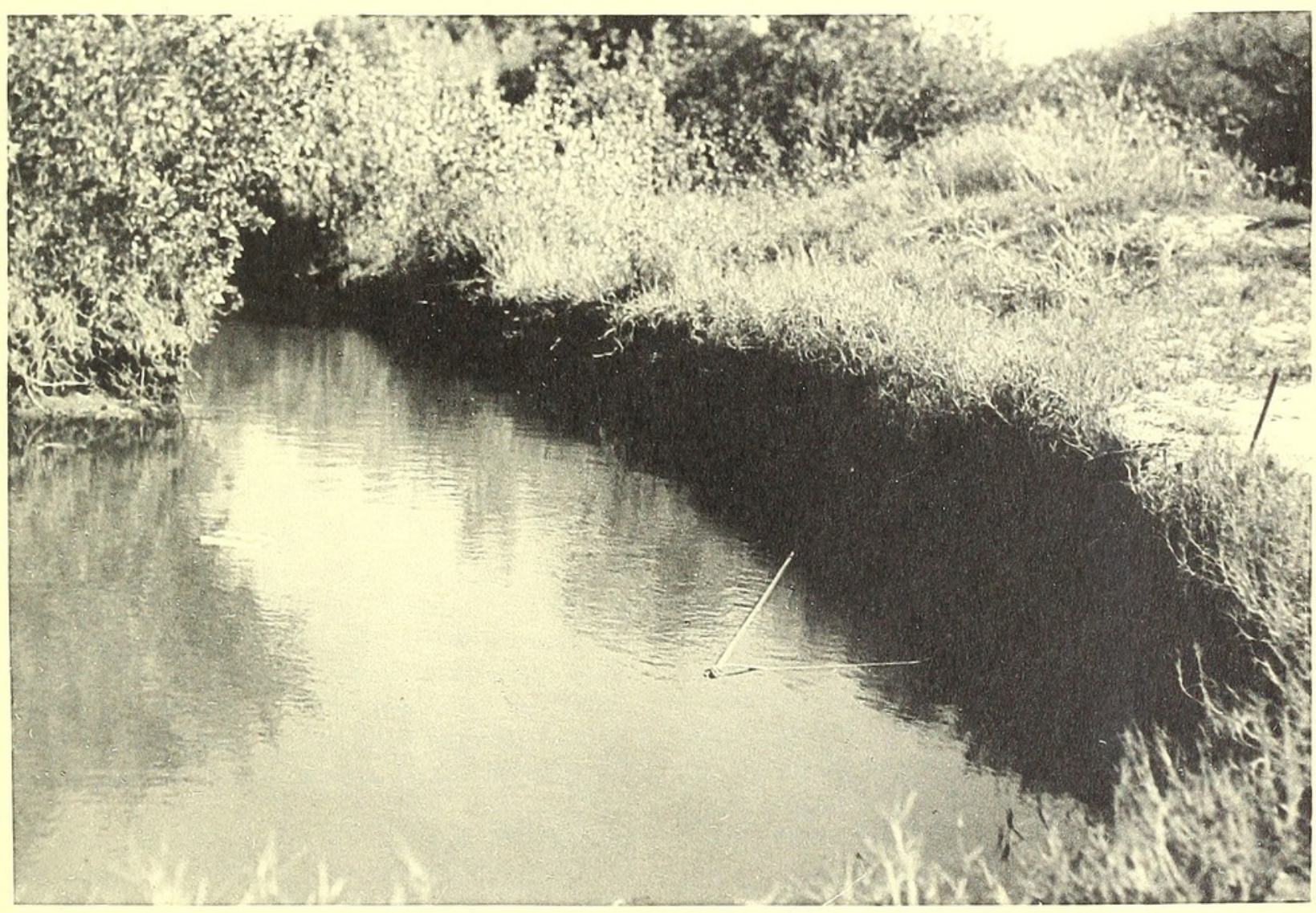

FIG. 7 


\section{$2 \mathrm{BHL}$ Biodiversity Heritage Library}

Breder, Charles M. 1960. "Design for a fry trap." Zoologica: scientific contributions of the New York Zoological Society 45(10), 155-160. https://doi.org/10.5962/p.203358.

View This Item Online: https://www.biodiversitylibrary.org/item/208290

DOI: https://doi.org/10.5962/p.203358

Permalink: https://www.biodiversitylibrary.org/partpdf/203358

\section{Holding Institution}

Smithsonian Libraries

\section{Sponsored by}

Biodiversity Heritage Library

\section{Copyright \& Reuse}

Copyright Status: In copyright. Digitized with the permission of the rights holder.

Rights Holder: Wildlife Conservation Society

This document was created from content at the Biodiversity Heritage Library, the world's largest open access digital library for biodiversity literature and archives. Visit BHL at https://www.biodiversitylibrary.org. 